\title{
Modeling the Peach Sugar Contents in Relation to Fruit Growth
}

\author{
Michel Génard ${ }^{1}$ and Michel Souty ${ }^{2}$ \\ Institut National de la Recherche Agronomique, Domaine Saint-Paul, Site Agroparc, 84914 Avignon \\ Cedex 9, France
}

Additional index words. Prunus persica, leaf : fruit ratio, carbon partitioning, sucrose, fructose, glucose, sorbitol, sweetness, quality

\begin{abstract}
The edible quality of peaches (Prunus persica $\mathbf{L}$. Batsch) to a great extent depends on their sweetness, which is related to sugar composition. Our objective was to develop a model to predict carbon partitioning within fruit flesh and to predict the sucrose, sorbitol, glucose, and fructose contents. The model is dynamic and deterministic and was designed to be driven by the flesh dry-weight growth curve, flesh water content, and temperature data. It uses differential equations where the state of the system is defined by variables that describe how much carbon is present as each form of sugar and as other compounds (acids and structural carbohydrates). The rates of change of these amounts of carbon depend on the current values of corresponding variables and on the transfer functions between them. These functions are defined by rate constants or by functions of degree-days after full bloom. The model was calibrated and tested using data sets from treatments that covered several leaf : fruit ratios. The predictions of the model were in fairly good agreement with experimental data. A sensitivity analysis was performed to identify the most influential transfer function parameters. Carbon flows between sugar forms were analyzed. Sucrose, which was the most abundant sugar, and fructose, which is the sweetest, contributed most to fruit sweetness. Simulations were performed to study the effects of changes in fruit growth-curve parameters on sugar contents and concentrations.
\end{abstract}

The quality of fleshy fruit, such as pears, cherries, or peaches, depends on their total sugar content (Leonard et al., 1953; Robertson et al., 1992) and the individual sugars that directly influence fruit flavor components like sweetness (Byrne et al., 1991; Robertson et al., 1988). Sucrose, glucose, fructose, and sorbitol are the main sugars or sugar alcohols encountered in the fruit of most rosaceous plants. Sweetness ranks as follows: fructose>sucrose>glucose> sorbitol (Doty, 1976; Pangborn 1963; Yamaguchi et al., 1970).

Many studies on the sugar content of fleshy fruit have focused on the conversion of phloem sugars (sucrose and sorbitol) within the fruit (Hansen, 1970) and on compositional changes during fruit growth and maturation (Ackerman et al., 1992; Chapman et al., 1991; Ishida et al., 1971). Pavel and DeJong (1993, 1995) focused on the accumulation and composition of sugars in peach and apple fruit in relation to relative fruit growth rate. They observed several phases corresponding to relative fruit growth rate patterns and suggested that these phases are related to changes in the physiological sink activity of fruit. Conceptual and comprehensive studies focused on the mechanisms involved in carbon metabolism within the fruit (Keener et al., 1979; Walker et al., 1978). The main enzymes implicated in sugar metabolism of fleshy fruit have been identified (Moriguchi et al., 1992; Yamaki and Ishikawa, 1986), but little is known about their regulation.

Current agricultural practices and cultivars result in wide variability of the sugar contents of fruit from one part of the plant to another (Dann and Jerie, 1988; Marini and Trout, 1984). This variation is caused by various factors, such as microclimatic gradients (Corelli-Grappadelli and Coston, 1991; Marini et al.,

Received for publication 4 Dec. 1995. Accepted for publication 18 June 1996. We thank G. Albagnac and F. Lescourret for their advice on this work; M. Bonafous, R. Laurent, and M. Reich for technical assistance; and P. Butler for improving the English translation. The cost of publishing this paper was defrayed in part by the payment of page charges. Under postal regulations, this paper therefore must be hereby marked advertisement solely to indicate this fact.

${ }^{1}$ Unité de Technologie des Produits Végétaux.

${ }^{2}$ Unité de Recherche en Ecophysiologie et Horticulture.
1991), leaf area around the fruit (Génard, 1992; Kliewer and Weaver, 1971), and vigor of fruit-bearing shoots (Génard and Bruchou, 1992). Microclimatic factors, such as temperature, act on carbohydrate breakdown for fruit respiration, whereas the leaf area or vigor of fruit-bearing shoots act on the level of carbohydrate supply to the fruit. Use of carbohydrates by the fruit and changes in sugar contents probably are interrelated strongly, which may explain the strong correlations usually noted between sugar content at harvest and size of fruit from the same tree (Génard et al., 1991).

Modeling the changes in sugar contents during fruit growth and ripening is an important task for physiologists and agronomists to build future simulation models of fruit quality useful for orchard management. Our aim is to provide the basis of such a model for peach fruit flesh during the final rapid-growth stage (stage III;

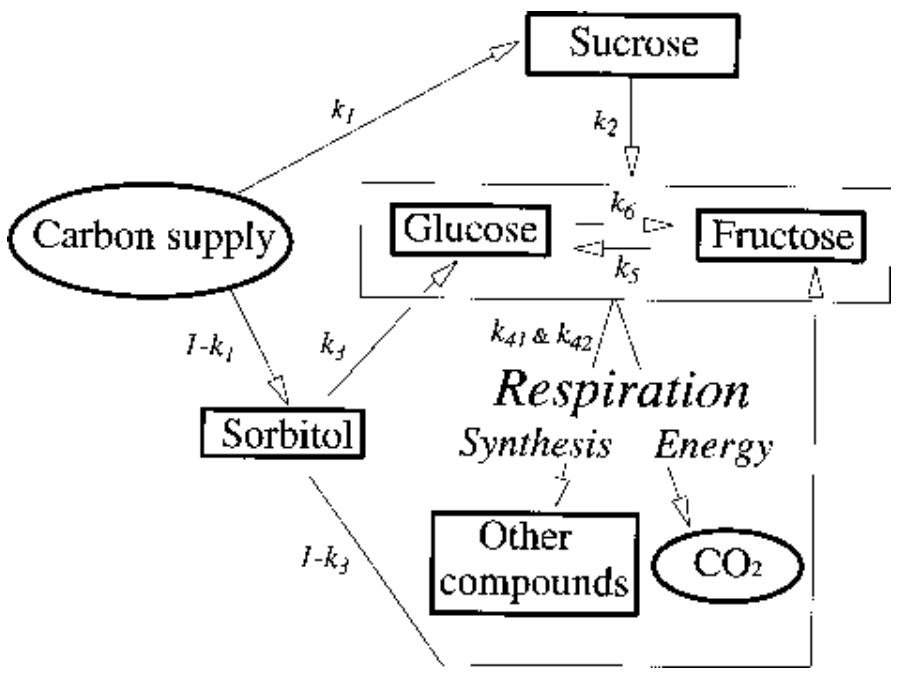

Fig. 1. Diagram illustrating the carbon partitioning by the model. Arrows, ellipses, and boxes represent carbon flows, carbon supply and losses, and carbohydrate components, respectively. The parameters implicated in each flow are indicated. 
Gage and Stutte, 1991). This species was chosen because of consumers' concern for quality (Bruhn et al., 1991). The model was designed to be driven by flesh dry-weight growth curve, flesh water content, and temperature. Model parametrization, simplification, and test of fit were presented. The model was analyzed through a sensitivity analysis of parameters, an analysis of carbon flow and of the contribution of the different sugars to fruit sweetness. Simulations were run to study the effects of changes in fruit growth curve on the sugar concentrations in the flesh.

The phloem sap of peach trees contains sucrose and sorbitol in almost equal quantities as the only sugars in the phloem (Moing et al., 1992). In the fruit, sucrose is the major sugar with $40 \%$ to $85 \%$ of total sugar content; glucose and fructose are present in equimolar quantities and can each reach $\approx 25 \%$ of total sugar content. The sorbitol content is always low (Brooks et al., 1993; Souty and André, 1975), which suggests that sorbitol is metabolized into reducing sugars. Moriguchi et al. (1990) demonstrated that sorbitol oxidase, which catalyzes the conversion of sorbitol into glucose, is an important enzyme of sorbitol metabolism in 'Hakuto' peach fruit. The various sorbitol dehydrogenases that convert sorbitol into fructose (Yamaki and Ishikawa, 1986) also may be important in other cultivars. Sucrose can arrive via the phloem into the fruit, be hydrolyzed into fructose and glucose by acid invertase and neutral invertase, or be synthesized from glucose and fructose by sucrose phosphate synthase (Keener et al., 1979; Yamaki and Asakura, 1988). Sucrose synthase, a reversible enzyme is implicated in synthesis and hydrolysis. Results on the importance of these enzymes are sometimes conflicting (Hubbard et al., 1991; Moriguchi et al., 1990; Vizzotto et al. 1996). Because glucose and fructose are absent from peach phloem sap (Moing et al., 1992), the balance between sucrose hydrolysis and synthesis in the fruit is probably in favor of hydrolysis. As the activity of the enzymes

Table 1. Model variables definition.

\begin{tabular}{|c|c|c|}
\hline Variable & Definition & Unit \\
\hline$\overline{\mathrm{C}_{\mathrm{fl}}}$ & Total amount of carbon in the fruit flesh & $\mathrm{g}$ \\
\hline $\mathrm{C}_{\mathrm{su}}$ & Amount of carbon as sucrose & $\mathrm{g}$ \\
\hline $\mathrm{C}_{\mathrm{so}}^{\mathrm{su}}$ & Amount of carbon as sorbitol & $\mathrm{g}$ \\
\hline $\mathrm{C}_{\mathrm{g}}$ & Amount of carbon as glucose & $\mathrm{g}$ \\
\hline $\mathrm{C}_{\mathrm{f}}^{\mathrm{g}}$ & Amount of carbon as fructose & $\mathrm{g}$ \\
\hline $\mathrm{C}_{\mathrm{o}}$ & $\begin{array}{l}\text { Amount of carbon as compounds other } \\
\text { than sugars }\end{array}$ & $\mathrm{g}$ \\
\hline$\frac{\mathrm{dC}_{\mathrm{ph}}}{\mathrm{dt}}$ & Phloem flow of carbon & $g \cdot d^{-1}$ \\
\hline$\frac{\mathrm{dC}_{\mathrm{r}}}{\mathrm{dt}}$ & Respiration flow of carbon & $g \cdot d^{-1}$ \\
\hline $\mathrm{K}_{2}$ & $\begin{array}{l}\text { Proportion of carbon present as sucrose } \\
\text { in the flesh that is converted every day } \\
\text { into glucose and fructose }\end{array}$ & $\mathrm{d}^{-1}$ \\
\hline $\mathrm{K}_{4}$ & $\begin{array}{l}\text { Proportion of carbon present as glucose } \\
\text { and fructose in the flesh that is } \\
\text { converted every day into compounds } \\
\text { other than sugars }\end{array}$ & $\mathrm{d}^{-1}$ \\
\hline SU & Sucrose concentration & $\mathrm{g} / 100 \mathrm{~g} \mathrm{fw}{ }^{\mathrm{Z}}$ \\
\hline SO & Sorbitol concentration & $\mathrm{g} / 100 \mathrm{~g} \mathrm{fw}$ \\
\hline G & Glucose concentration & $\mathrm{g} / 100 \mathrm{~g} \mathrm{fw}$ \\
\hline $\mathrm{F}$ & Fructose concentration & $\mathrm{g} / 100 \mathrm{~g} \mathrm{fw}$ \\
\hline DW & Flesh dry weight & $\mathrm{g}$ \\
\hline FW & Flesh fresh weight & $\mathrm{g}$ \\
\hline $\mathrm{RSw}_{\mathrm{i}}$ & Relative sweetness of a sugar i & \\
\hline
\end{tabular}

${ }^{\mathrm{z}} \mathrm{fw}=$ fresh weight. implicated in sucrose hydrolysis and synthesis decreases and remains unvarying or increases during fruit growth, respectively, the balance between sucrose and reducing sugars shifts toward sucrose (Hubbard et al., 1991; Vizzotto et al., 1996). We assumed that glucose and fructose can be interconverted as shown in apple, apricot, and tomato fruit, (Hansen, 1970; Reid and Bieleski, 1974; Walker et al., 1978). These two sugars are used as substrates for $\mathrm{CO}_{2}$ production and for synthesis of compounds other than sugars (e.g., starch, acids, structural carbohydrates, and proteins) through respiratory pathways. Pavel and DeJong's (1993) results on peaches indicate a seasonal decrease in the proportion of these other compounds in the fruit.

These data were incorporated in a model summarized in Fig. 1, which simulates the partitioning of the flow of carbon from the phloem into the four previously mentioned sugars, the other compounds in the fruit, and the $\mathrm{CO}_{2}$ produced through respiration.

The model relies on seven main assumptions: 1) the distribution of incoming carbon into sucrose and sorbitol unloading is constant; 2) the carbon present in the fruit as sorbitol is continuously converted into glucose and fructose; 3 ) the transformation of carbon from sucrose into glucose and fructose decreases as degreedays after flowering accumulate; 4) glucose and fructose can be interconverted; 5) the amount of carbon used for synthesizing compounds other than sugars decreases as degree-days accumulate and comes from glucose and fructose through respiratory pathways; 6) the carbon used for respiration comes from glucose and fructose proportional to their quantity in the fruit (maintenance respiration of flesh is assumed to be proportional to flesh dry weight and temperature and growth respiration to growth rate in terms of dry matter); and 7) except for respiration, the carbon flow between two compounds is proportional to the quantity of carbon in the source compound.

Thus, we can represent the system by the following set of differential and algebraic equations:

$$
\begin{aligned}
& \frac{\mathrm{dC}_{\mathrm{so}}}{\mathrm{dt}}=\left(1-\mathrm{k}_{1}\right) \frac{\mathrm{dC}_{\mathrm{ph}}}{\mathrm{dt}}-\mathrm{C}_{\mathrm{so}} \\
& \frac{\mathrm{dC}_{\mathrm{su}}}{\mathrm{dt}}=\mathrm{k}_{1} \frac{\mathrm{dC}_{\mathrm{ph}}}{\mathrm{dt}}-\mathrm{K}_{2} \mathrm{C}_{\mathrm{su}} \\
& \frac{\mathrm{dC}_{\mathrm{g}}}{\mathrm{dt}}=\frac{\mathrm{K}_{2}}{2} \mathrm{C}_{\mathrm{su}}+\mathrm{k}_{3} \mathrm{C}_{\mathrm{so}}-\mathrm{K}_{4} \mathrm{C}_{\mathrm{g}}+\mathrm{k}_{5} \mathrm{C}_{\mathrm{f}}-\mathrm{k}_{6} \mathrm{C}_{\mathrm{g}}-\frac{\mathrm{C}_{\mathrm{g}}}{\mathrm{C}_{\mathrm{g}}+\mathrm{C}_{\mathrm{f}}} \times \frac{\mathrm{dC}_{\mathrm{r}}}{\mathrm{dt}} \\
& \frac{\mathrm{dC}_{\mathrm{f}}}{\mathrm{dt}}=\frac{\mathrm{K}_{2}}{2} \mathrm{C}_{\mathrm{su}}+\left(1-\mathrm{k}_{3}\right) \mathrm{C}_{\mathrm{so}}-\mathrm{K}_{4} \mathrm{C}_{\mathrm{f}}-\mathrm{k}_{5} \mathrm{C}_{\mathrm{f}}+\mathrm{k}_{6} \mathrm{C}_{\mathrm{g}}-\frac{\mathrm{C}_{\mathrm{f}}}{\mathrm{C}_{\mathrm{g}}+\mathrm{C}_{\mathrm{f}}} \times \frac{\mathrm{dC}_{\mathrm{r}}}{\mathrm{dt}} \\
& \mathrm{C}_{\mathrm{o}}=\mathrm{C}_{\mathrm{fl}}-\mathrm{C}_{\mathrm{su}}-\mathrm{C}_{\mathrm{so}}-\mathrm{C}_{\mathrm{g}}-\mathrm{C}_{\mathrm{f}} \\
& \text { with } \mathrm{K}_{2}=\mathrm{e}^{-\mathrm{k}_{2} \mathrm{dd}} \text { and } \mathrm{K}_{4}=\mathrm{k}_{41}\left(1-\frac{\mathrm{dd}}{\mathrm{k}_{42}}\right)
\end{aligned}
$$

where: $\mathrm{C}_{\mathrm{fl}}$ is the total amount of carbon (in grams) in the fruit flesh and $\mathrm{C}_{\mathrm{su}}, \mathrm{C}_{\mathrm{so}}, \mathrm{C}_{\mathrm{g}}, \mathrm{C}_{\mathrm{f}}$, and $\mathrm{C}_{\mathrm{o}}$ the amounts of carbon (in grams) as sucrose, sorbitol, glucose, fructose, and compounds other than sugars, respectively; $\frac{\mathrm{dC}_{\mathrm{ph}}}{\mathrm{dt}}$ and $\frac{\mathrm{dC}_{\mathrm{r}}}{\mathrm{dt}}$ are the phloem and respiration flows of carbon (in grams per day) into and out of the fruit, respectively; $\mathrm{k}_{\mathrm{i}}$ are parameters and dd is the degree-days after full bloom calculated according to the lower temperature threshold used by DeJong and Goudriaan (1989) for peach fruit $\left(7^{\circ} \mathrm{C}\right) ; \mathrm{K}_{2}$ is the proportion of carbon present as sucrose in the flesh that is converted every day into glucose and fructose; and $\mathrm{K}_{4}$ is the proportion of carbon present as glucose and fructose that is converted every day into compounds other than sugars.

The model computes the total amount of carbon in the fruit 
Table 2. Model parameters: definition, units, values, and SD (where estimated).

\begin{tabular}{|c|c|c|c|c|}
\hline Parameter & Definition & Unit & $\begin{array}{l}\text { Value } \\
\text { (SD) }\end{array}$ & Reference \\
\hline$\overline{\mathrm{k}_{1}}$ & $\begin{array}{l}\text { Percentage of phloemic } \mathrm{C} \text { unloaded } \\
\text { as sucrose }\end{array}$ & & 0.54 & Moing et al. (1992) \\
\hline $\mathrm{k}_{2}$ & $\begin{array}{l}\text { Coefficient of the transfer function } \\
\text { between sucrose and glucose-fructose }\end{array}$ & degree- $\mathrm{d}^{-1}$ & $\begin{array}{l}0.00308 \\
(510-5)\end{array}$ & \\
\hline $\mathrm{k}_{3}$ & $\begin{array}{l}\text { Coefficient of the transfer function } \\
\text { between sorbitol and glucose }\end{array}$ & $d^{-1}$ & $\begin{array}{c}0.438 \\
(0.014)\end{array}$ & \\
\hline $\mathrm{k}_{41}$ & $\begin{array}{l}\text { Coefficient of the transfer function between } \\
\text { glucose-fructose and other compounds }\end{array}$ & $d^{-1}$ & $\begin{array}{c}0.173 \\
(0.010)\end{array}$ & \\
\hline $\mathrm{k}_{42}$ & $\begin{array}{l}\text { Coefficient of transfer function between } \\
\text { glucose-fructose and other compounds }\end{array}$ & degree-d & $\begin{array}{l}1848 \\
(47.0)\end{array}$ & \\
\hline $\mathrm{c}_{\mathrm{fl}}$ & Carbon content in peach flesh & g carbon/g DW & $\begin{array}{c}0.445 \\
(0.012)\end{array}$ & \\
\hline gc & Growth respiration coefficient & g carbon/g DW & 0.084 & DeJong and Goudrian (1989) \\
\hline $\mathrm{m}$ & Maintenance respiration coefficient & g carbon/g DW/degree-d $\mathrm{d}^{-1}$ & 0.00005 & DeJong and Goudrian (1989) \\
\hline$\theta$ & $\begin{array}{l}\text { Temperature threshold for } \\
\text { degree-days computation }\end{array}$ & ${ }^{\circ} \mathrm{C}$ & 7 & DeJong and Goudrian (1989) \\
\hline $\mathrm{c}_{\mathrm{su}}$ & Carbon content of sucrose & g carbon/g sucrose & 0.421 & \\
\hline $\mathrm{c}_{\mathrm{so}}$ & Carbon content of sorbitol & g carbon/g sorbitol & 0.395 & \\
\hline$c_{g}$ & Carbon content of glucose & $\mathrm{g}$ carbon/g glucose & 0.4 & \\
\hline$c_{f}^{g}$ & Carbon content of fructose & $\mathrm{g}$ carbon/g fructose & 0.4 & \\
\hline $\mathrm{r}_{1}$ & Sweetness rating of sucrose & & 1 & Kulp et al. (1991) \\
\hline$r_{2}$ & Sweetness rating of fructose & & 1.75 & Kulp et al. (1991) \\
\hline $\mathrm{r}_{3}$ & Sweetness rating of glucose & & 0.77 & Kulp et al. (1991) \\
\hline $\mathrm{r}_{4}$ & Sweetness rating of sorbitol & & 0.6 & Kulp et al. (1991) \\
\hline
\end{tabular}

flesh, the respiration losses, and the phloem flow with the following equations:

$\mathrm{C}_{\mathrm{fl}}=\mathrm{c}_{\mathrm{fl}} \mathrm{DW}$

where DW is the flesh dry weight (in grams) and $c_{\mathrm{fl}}$ its carbon content (in grams of carbon per grams of dry weight) assumed to be constant throughout stage III of growth.

$\frac{\mathrm{dC}_{\mathrm{r}}}{\mathrm{dt}}=\mathrm{gc} \frac{\mathrm{dDW}}{\mathrm{dt}}+\mathrm{mDW}($ temp $-\theta)$

where gc (in grams of carbon per gram of dry weight) is the growth respiration coefficient, $m$ (in grams of carbon per gram of dry weight and per degree-day) the maintenance respiration coefficient, $\theta$ a temperature threshhold, and temp the temperature.

$\frac{\mathrm{dC}_{\mathrm{ph}}}{\mathrm{dt}}=\frac{\mathrm{dC}_{\mathrm{fl}}}{\mathrm{dt}}+\frac{\mathrm{dC}_{\mathrm{r}}}{\mathrm{dt}}$

The sugar concentrations (grams per $100 \mathrm{~g}$ fresh weight) are computed as:

$\mathrm{SU}=\frac{100 \mathrm{C}_{\mathrm{su}}}{\mathrm{c}_{\mathrm{su}} \mathrm{FW}}, \mathrm{SO}=\frac{100 \mathrm{C}_{\mathrm{so}}}{\mathrm{c}_{\mathrm{so}} \mathrm{FW}}, \mathrm{G}=\frac{100 \mathrm{C}_{\mathrm{g}}}{\mathrm{c}_{\mathrm{g}} \mathrm{FW}}, \mathrm{F}=\frac{100 \mathrm{C}_{\mathrm{f}}}{\mathrm{c}_{\mathrm{f}} \mathrm{FW}}$

where $\mathrm{c}_{\mathrm{su}}, \mathrm{c}_{\mathrm{so}}, \mathrm{c}_{\mathrm{g}}$, and $\mathrm{c}_{\mathrm{f}}$ are the carbon content of $1 \mathrm{~g}$ sucrose, sorbitol, glucose, and fructose, respectively.

FW (in grams) is the flesh fresh weight computed as a function of flesh dry weight:

$\mathrm{FW}=\frac{\mathrm{DW}}{1-\mathrm{WC}}$

where wc is the flesh water content (in grams of water per gram of fresh weight). This parameter increased only slightly over time (data not shown); it was assumed to be constant for the model.
The relative sweetness of a sugar $i$ is computed as :

$$
\mathrm{RSw}_{\mathrm{i}}=\frac{\mathrm{r}_{\mathrm{i}} \times \mathrm{X}_{\mathrm{i}}}{\sum_{\mathrm{j}=1}^{4} \mathrm{r}_{\mathrm{j}} \times \mathrm{X}_{\mathrm{j}}}
$$

where $\mathrm{X}_{\mathrm{i}}$ is its concentration and $\mathrm{r}_{\mathrm{i}}$ its sweetness rating.

The definitions of variables and of parameters are indicated in Tables 1 and 2 .

\section{Materials and Methods}

Leaf: fruit ratio experiment. Field treatments with different leaf : fruit ratios were used to obtain contrasted growing conditions in an experiment used to parametrize, simplify, and test the model. The experiment was performed on 12-year-old peach trees planted in the orchard of the Institut National de la Recherche Agronomique Avignon Centre from the beginning of June to mid-Aug. 1993. The fruit were in stage III of growth. Their flesh firmness increased until 22 June then decreased regularly until a minimum reached on 2 Aug. at the beginning of the ripening period. The latter period also was characterized by a high ethylene production (data not shown). The cultivar used was the late maturing 'Suncrest'/GF 677. Trees were goblet trained and received routine horticultural care. The treatments ( $\mathrm{t} 6, \mathrm{t} 18$, and $\mathrm{t} 30$ ) were leaf : fruit ratios of 6 , 18 , and 30 leaves per fruit, respectively. These treatments were chosen to obtain minimum, mean, and maximum growth curves representative of the 'Suncrest' cultivar. They were applied to similar fruit-bearing shoots isolated from the tree by girdling and were located on the southern part of each tree for the sake of homogeneity with respect to initial conditions. The leaf : fruit ratios were established, and shoots were girdled at the beginning of June (beginning of stage III of growth). Shoots with six or 18 
leaves per fruit were thinned to four fruit and shoots with 30 leaves per fruit to three fruit. Thus treatments t6, t18, and $\mathrm{t} 30$ had 24, 72, and 90 leaves per shoot, respectively.

Two hundred and forty fruit-bearing shoots were arranged on 45 trees to obtain 80 sets of three neighboring shoots with different leaf : fruit ratios. Two sets of the three treatments were applied to 35 trees and one set to the remaining 10 trees. A replicate was constituted of fruit from one shoot from 28 June to 16 Aug. and of fruit from two shoots from 7 to 22 June to have enough fruit flesh

Table 3. Parameter values for the maximal, mean, and minimal logistic functions fitted to the flesh dry-weight (DW) data of each treatment.

\begin{tabular}{|c|c|c|c|c|c|c|}
\hline \multirow[b]{2}{*}{ Treatment } & \multirow[b]{2}{*}{ Function } & \multicolumn{4}{|c|}{ Parameter values } & \multirow[b]{2}{*}{$R^{2}$} \\
\hline & & $\begin{array}{c}a_{1} \\
(\mathrm{~g} \mathrm{DW})\end{array}$ & $\begin{array}{c}a_{2} \\
(\mathrm{~g} \mathrm{DW})\end{array}$ & $\begin{array}{c}a_{3} \\
(\mathrm{~g} \mathrm{DW} / \mathrm{d})\end{array}$ & $\begin{array}{l}a_{4} \\
\text { (d) }\end{array}$ & \\
\hline \multirow[t]{3}{*}{ t6 } & Minimal & 0 & 6.5 & 0.2 & 30 & \\
\hline & Mean & 0 & 10.8 & 0.37 & 41.6 & 0.55 \\
\hline & Maximal & 0 & 17 & 0.75 & 45 & \\
\hline \multirow[t]{3}{*}{$\mathrm{t} 18$} & Minimal & 2.04 & 10 & 1 & 28 & \\
\hline & Mean & 2.04 & 16.7 & 1.25 & 34.3 & 0.80 \\
\hline & Maximal & 2.04 & 22 & 1.5 & 36 & \\
\hline \multirow[t]{3}{*}{$\mathrm{t} 30$} & Minimal & 2.48 & 16 & 1.5 & 30 & \\
\hline & Mean & 2.48 & 26.1 & 2.15 & 35.3 & 0.80 \\
\hline & Maximal & 2.48 & 38 & 2.8 & 40 & \\
\hline
\end{tabular}

for analysis of fruit composition when fruit were small. Fruit from five replicates were harvested each week during the 8 weeks from 7 June to the beginning of fruit ripening on 2 Aug. During the ripening period, the fruit were harvested every 2 to $4 \mathrm{~d}$ when the fruit were soft and ground color was yellow. Eleven to 22 replicates per treatment were harvested. The last fruit were harvested on 16 Aug.

The flesh carbon content $\left(\mathrm{c}_{\mathrm{fl}}\right)$ was measured on a sample of 13 to 15 fruit harvested randomly in the same orchard the 6 and 30 June and 25 July 1994.

Determining fruit composition. At each harvest of the 1993 experiment, the fresh and dry weights of fruit flesh were measured after peeling and stoning. The fruit flesh of each replicate was frozen in liquid $\mathrm{N}$ and pulverized with a 300 Dangoumill ball crusher (Prolabo, Paris) for 2 min. Twenty grams of this powder were homogenized with 80 $\mathrm{mL}$ of distilled water with a homogenizer (Polytron PTA10-35, Kinematica Gmbh, Luzern, Switzerland); the slurry was centrifuged $10 \mathrm{~min}$ at $2500 \mathrm{~g}$, and the
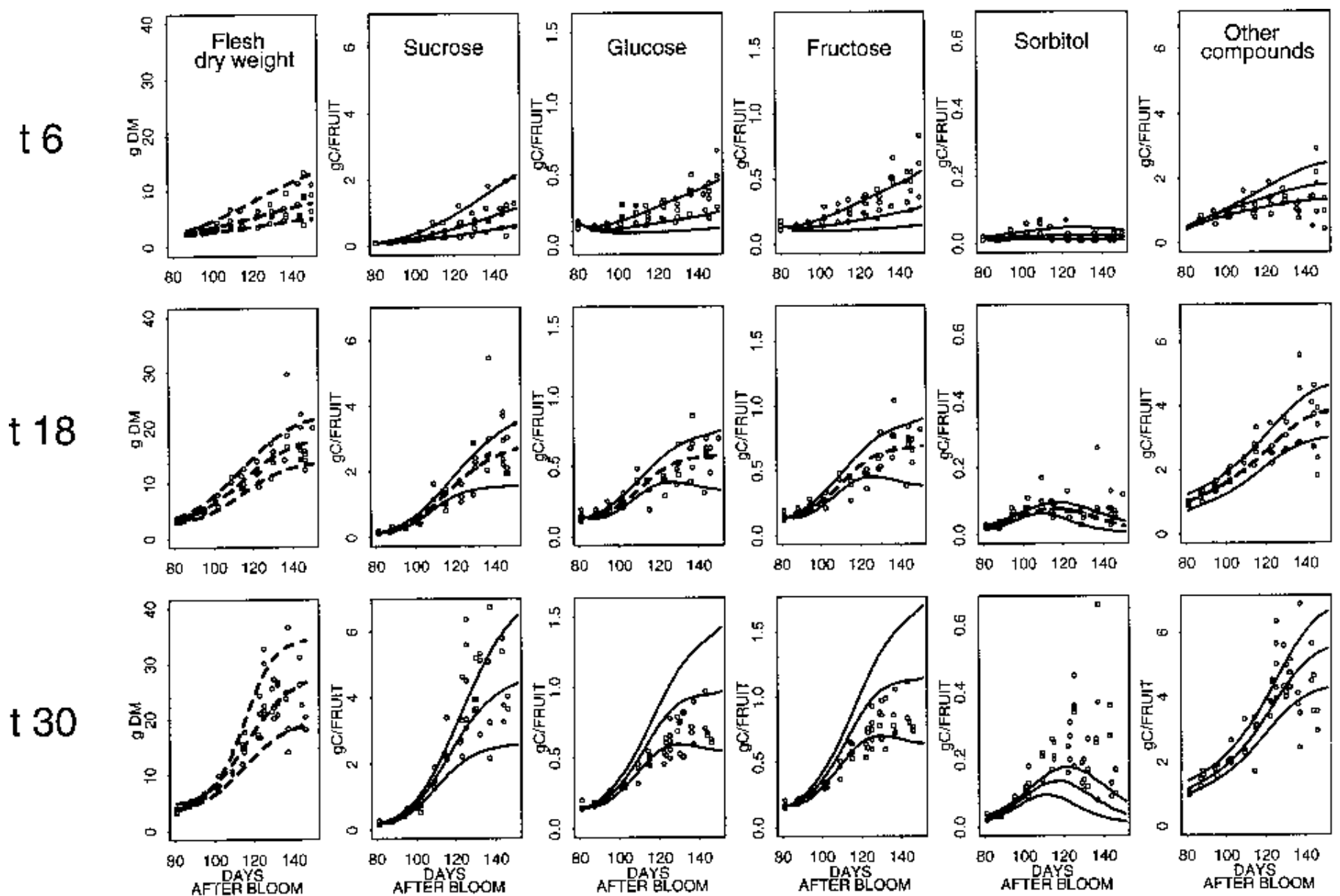

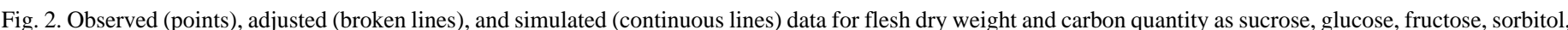

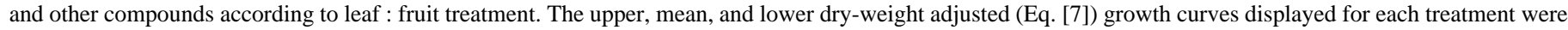

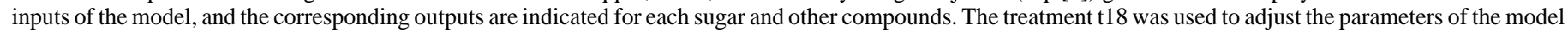
based on the corresponding mean adjusted growth curve. 
resulting supernatant stored at $-20^{\circ} \mathrm{C}$ for later evaluation of sugars by HPLC.

For HPLC analysis, thawed supernatant was filtered on a C18 Sep-Pack column (Waters-Millipure Corp., Milford, Ma.) and a 0.45-mm Acrodisc cartridge (Gelman Science, Ann Arbor, Mich.). HPLC analyses were performed on a chromatograph (Varian Associates, Walnut Creek, Calif) [model 9010 pump (Varian) with a model 7125 Rheodyne valve (Cotati, Calif.) using a Sugar Pack 1 column (Waters-Millipore Corp., Milford, Mass.) at $85^{\circ} \mathrm{C}$, and sugars were detected with a refractive index detector (RI-4, Varian). External standard solutions of sucrose, glucose, fructose, and sorbitol were used to quantify eluted peaks with the Star Chromatography Workstation software.

The carbon content per unit dry weight was determined on the fruit harvested in 1994. The flesh of each fruit was frozen in liquid $\mathrm{N}$ and pulverized. A random sampling of $4 \mathrm{mg}$ of this mesocarp powder was analyzed for carbon content by flash combustion at $1700^{\circ} \mathrm{C}$.

Model inputs. The temperature, the flesh water content, and the flesh dry-weight growth curve are used as inputs. DW was estimated by fitting a logistic function to the DW data for each treatment:

$$
\mathrm{DW}=\mathrm{a}_{1}+\frac{\mathrm{a}_{2}}{1+\mathrm{e}^{-\frac{\mathrm{a}_{3}\left(\mathrm{DAB}-\mathrm{DAB}_{0}-\mathrm{a}_{4}\right)}{\mathrm{a}_{2}}}}
$$

where $a_{i}$ are parameters, DAB is the number of days after full bloom, and $\mathrm{DAB}_{0}$ is the number of days after full bloom at the beginning of stage III of fruit growth. Maximum dry weight is

$\operatorname{DWmax}=\mathrm{a}_{1}+\mathrm{a}_{2}$

Parameter $\mathrm{a}_{3}$ is proportional to the maximum growth rate at time $\mathrm{a}_{4}$, which is the date of the maximal absolute growth rate (in days after start of growth stage III of fruit growth).

The parameters $a_{i}$ used to calculate the flesh dry weight were estimated for each treatment by a nonlinear least squares method using the Gauss-Newton algorithm (Chambers and Hastie, 1992).

Table 4. Minimal, mean, and maximal flesh water-content (grams water/ grams fresh weight) values of each treatment. Different letters indicate that means significantly differ between leaf : fruit ratio treatments at $P$ $<0.001$ (Kruskal-Wallis and Noether tests).

\begin{tabular}{llll}
\hline \hline & \multicolumn{3}{c}{ Leaf : fruit ratio } \\
\cline { 2 - 4 } Variable & \multicolumn{1}{c}{6} & 18 & 30 \\
\hline Minimal & 0.840 & 0.840 & 0.810 \\
Mean & $0.895 \mathrm{a}$ & $0.870 \mathrm{~b}$ & $0.854 \mathrm{c}$ \\
Maximal & 0.920 & 0.910 & 0.880 \\
\hline
\end{tabular}

The percentage of explained variation was estimated as recommended by Steiner et al. (1993).

Model solving, parameterization, simplification, and test of fit. The differential equations are solved numerically by the first order Runge Kutta method (Steiner et al., 1993). The step size is $1 \mathrm{~d}$.

The flesh carbon content $\left(\mathrm{c}_{\mathrm{f}}\right)$ was calculated by averaging the measures taken at the three dates because it was almost constant over time. Parameter $\mathrm{k}_{1}$ was taken from Moing et al. (1992). Values of $\mathrm{gc}, \mathrm{m}$, and $\theta$ in the peach tree were taken from DeJong and Goudriaan (1989). The sweetness ratings $\left(r_{i}\right)$ were taken from Kulp et al. (1991). The values of parameters are indicated in Table 2.

The model was fitted to the 18-leaf to fruit ratio data (t18), which were the amount of carbon in fruit flesh as sucrose, sorbitol, glucose, fructose, and compounds other than sugar. Thus, only Eqs. [1], [2], [3], and [4] were used for fitting. The variability of errors is modeled by $s^{2}=\omega^{2} \mathrm{f}^{\gamma}$, where $\mathrm{s}$ is the SD of the modeled variable, $\mathrm{f}$ is the predicted value, $\omega$ is a proportionality factor, and $\gamma$ is an adjustable heteroscedasticity parameter.

Parameters $\gamma$ and $\mathrm{k}_{\mathrm{i}}$, other than $\mathrm{k}_{1}$, were estimated by maximizing likelihood using the Nelder-Mead direct-search method that is implemented in the SimuSolv software (Steiner et al., 1993). Using the log of the likelihood function, the probability of obtaining our set of measured values was calculated, assuming that the model with its current set of adjustable parameter values was correct. Using the optimization algorithm, the values of adjustable parameters were systematically changed until we obtained that set of values that maximizes the log likelihood function. The resulting values yielded the highest calculated probability of obtaining the data we did. By inference, then, we take that set of values as being the most likely to be correct. Nelder-Mead direct-search optimization algorithm solely uses values of the objective function to determine the direction to search. Because derivatives are not used, the method is not sensitive to irregular or discontinuous functions. The percentage of explained variation was estimated as recommended by Steiner et al. (1993).

The complete model was simplified in various ways by neglecting relationships (i.e., by assigning fixed values to some of the parameters) to reduce the number of uncorrelated parameters that were estimated. The difference between the complete and the simplified models then was tested by comparing the likelihood functions as presented by Steiner et al. (1993). Among two models showing no significant difference with respect to likelihood, the simplest was preferred. The statistic used to compare two models with $p$ and $q$ parameters, respectively, was minus two-times the log of the likelihood ratio, which follows a $\chi^{2}$ distribution with $\mathrm{p}$ and q degrees of freedom.

The best simplified model was subsequently used to predict the carbon partitioning in six and 30 leaves per fruit treatments, allowing the test of fit of the model to be determined with respect to fruit growth. Moreover, we tested whether the between-fruit variability of growth observed in our data sets within each treatment could explain the variability of carbon levels as each form of sugar by choosing empirically the $\mathrm{a}_{\mathrm{i}}$ and wc corresponding to the upper and lower range of each treatment.

Model analysis. A sensitivity analysis was performed to identify the most influential $k_{i}$ param- 
eters on the model responses. The sensitivity of the system response to changes in parameters values was expressed quantitatively from the sensitivity coefficients, defined as the partial derivatives of the model responses with respect to the parameters (Steiner et al., 1993). The interpretation of the sensitivity coefficients is referred to as local sensitivity analysis since these coefficients provide information on the effect of small changes in the parameters on the model responses. They do not provide information on the effect of simultaneous or large parameter changes. Bias due to differences in the magnitude of parameters values was eliminated by normalizing the sensitivity coefficients.

Finally, the model was used for simulating the effects of maximum dry weight (DWmax), maximum growth rate $\left(a_{3}\right)$, and date of the maximum absolute growth rate $\left(a_{4}\right)$ on the sugar concentrations in the flesh. Initial dry weight $\left(\mathrm{DW}_{0}\right)$ was assumed to remain constant in these simulations. Using Eqs. [7] and [8], we calculated the $\mathrm{a}_{2}$ value for each set of DWmax, $\mathrm{a}_{3}$, and $\mathrm{a}_{4}$ values by solving the following equation in $\mathrm{a}_{2}$, using the root finder for continuous functions of the Splus software (Chambers and Hastie, 1992): $D W_{0}-D W m a x+a_{2}-\frac{a_{2}}{1+e^{\frac{a_{3} a_{4}}{a_{2}}}}=0$. The value of $a_{1}$ then was calculated from Eq. [8].

\section{Results}

Fruit growth and flesh water content. The logistic model of Eq. [7], respectively explained $55 \%, 80 \%$, and $80 \%$ of the flesh dry-
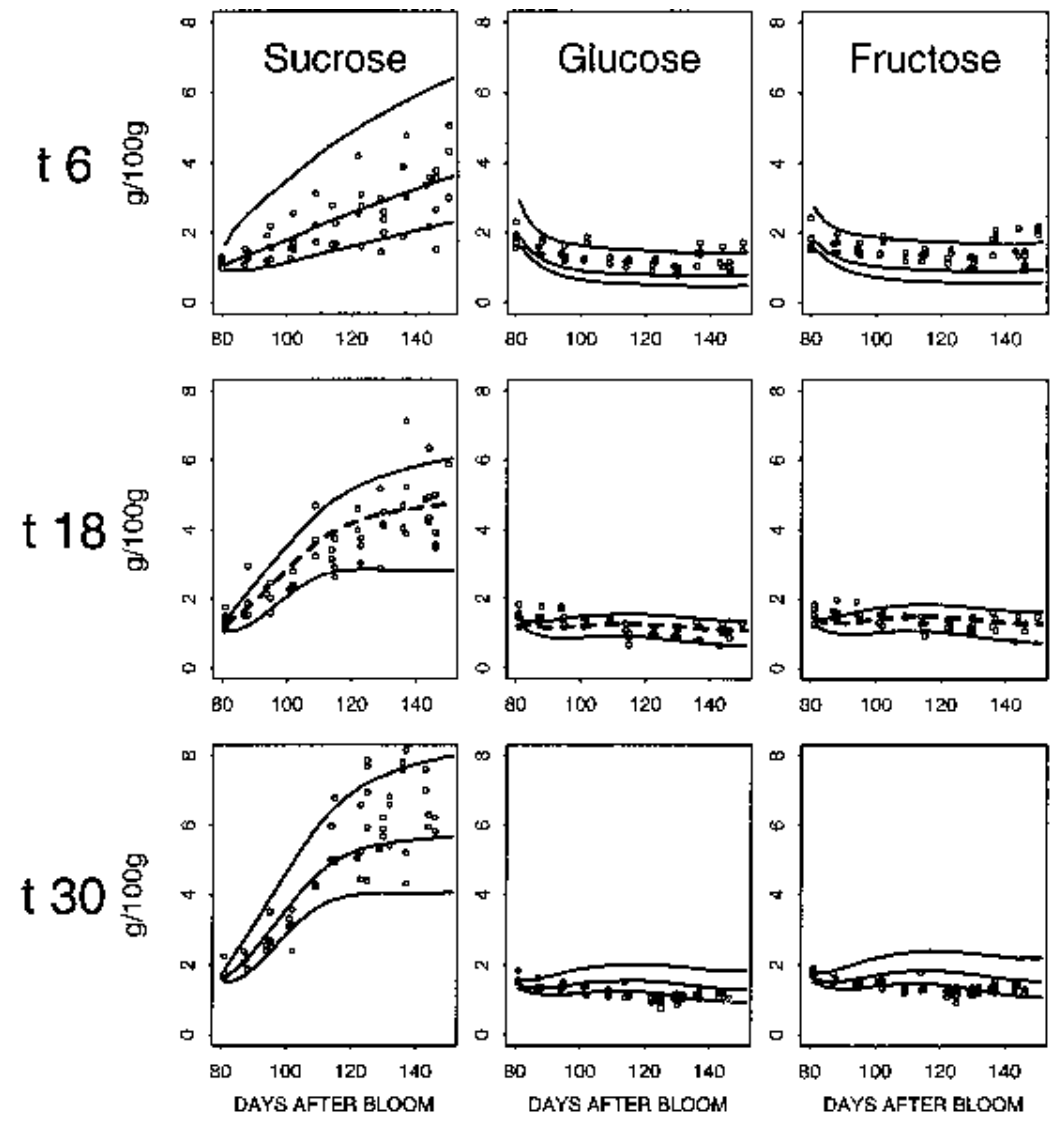

Fig. 3. Observed (points), adjusted (broken lines), and simulated (continuous lines) data for sugars concentrations (grams sugar/100 grams fresh weight) in fruit flesh according to leaf : fruit treatment. The three lines of each graph are the outputs of the model, corresponding to the upper, the mean, and the lower dry-weight growth curves displayed in Fig. 2 and to the minimum, mean, and maximum flesh water contents indicated in Table 3 . The treatment t18 was used to adjust the parameters of the model on the basis of the corresponding mean adjusted growth curve.
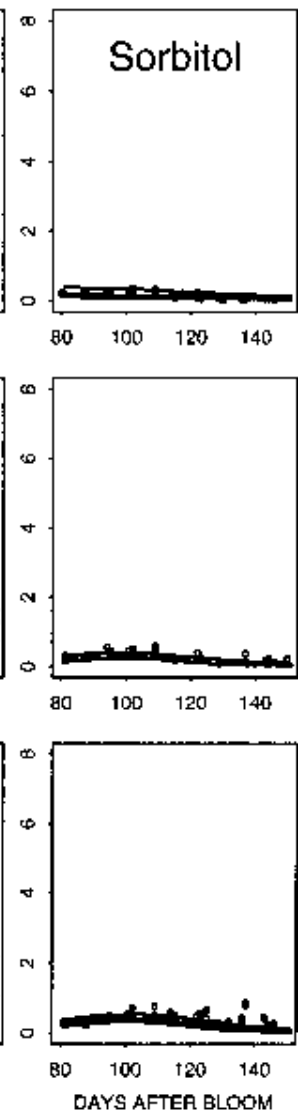

weight variance for 6,18 , and 30 leaf : fruit ratios (Table 3). Variability within treatments was significant and increased with me the The parameter values estimated for the logistic model for fruit growth. The flesh water content decreased significantly with eaf : fruit ratio and, thus, with the intensity of fruit growth. For a treatment, we associated maximal and minimal fruit growt

(Table 4). 18 leaf : fruit data explained $81 \%$ of the variability. However, fructose $\left(\mathrm{k}_{3}=1\right)$, under the assumption that sorbitol is predominantly converted to glucose (Moriguchi et al., 1990). Results of 列 case where reactions between glucose and fructose were suppressed $\left(\mathrm{k}_{5}=0\right.$ and $\left.\mathrm{k}_{6}=0\right)$ gave the same value for the log likelihood function as the complete model while avoiding high correlation 5) $5)$ for which only four parameters have to be estimated (Table 2). Data and curves generated by the fitted model are shown in Fig. 2. The model explained $90 \%, 52 \%$, $82 \%, 88 \%$, and $83 \%$ of the variation of carbon (in grams per fruit) as sucrose, sorbitol, glucose, fructose, and compounds other than sugars, respectively. The heteroscedasticity parameter of the error model was always equal to 2 , which means that the SD of the carbon content increased with its mean value for each compound. The model also was used to simulate the seasonal variation of sugar concentrations. Experimental and simulated data agreed well for sucrose and sorbitol. However, only the order of magnitude was correctly predicted for reducing sugar concentrations (Fig. 3).

Model test of fit. Simulated carbon content per fruit data for six and 30 leaf : fruit treatments agreed fairly well with experimental results (Fig. 2), but reducing sugars were underestimated for $\mathrm{t} 6$ and overestimated for $\mathrm{t} 30$. The model predicted the seasonal variations of the sucrose and sorbitol concentrations fairly well, but only the order of magnitude was correct for reducing sugars (Fig. 3). The model predicted the ranking of treatments for each sugar well $(\mathrm{t} 6<\mathrm{t} 18<\mathrm{t} 30$ for sucrose and sorbitol; $\mathrm{t} 6 \approx \mathrm{t} 18 \approx \mathrm{t} 30$ for reducing sugar). The variability of carbon content and sugar con- 
centrations within treatments was depicted well by the model (Figs. 2 and 3).

Model analysis. A sensitivity analysis performed for the 18 leaf : fruit treatment showed that $\mathrm{k}_{\mathrm{i}}$ parameters greatly influenced the carbon partitioning. The structure of the model resulted in sorbitol being sensitive to variations of $\mathrm{k}_{1}$ only. Parameter $\mathrm{k}_{2}$ affected all other compartments; $\mathrm{k}_{3}$ affected glucose and fructose; and $\mathrm{k}_{41}$ and $\mathrm{k}_{42}$ affected glucose, fructose, and compounds other than sugars (Fig. 4). Parameter $k_{42}$, which is the sum of degree-days for which the carbon flow between reducing sugars and compounds other than sugars is 0 , greatly affected the estimation of reducing sugars and compounds other than sugars.

The carbon supply per fruit varied during the season from 0.05 to $0.17 \mathrm{~g} \cdot \mathrm{d}^{-1}$. The proportion of carbon present as sucrose in the flesh converted every day into glucose and fructose $\left(\mathrm{K}_{2}\right)$, decreased with time from $13 \%$ to almost $0 \%$. The percentage of carbon present as sorbitol that was used each day for glucose synthesis $\left(\mathrm{k}_{3}\right)$ was assumed to be constant in the model and was estimated as 44\%; the remaining 56\% was used for fructose synthesis. The percentage of carbon present as glucose and fructose that was converted daily into compounds other than sugars $\left(\mathrm{K}_{4}\right)$ decreased seasonally from $11 \%$ to almost $0 \%$. Only $1 \%$ to $5 \%$ of the carbon present as glucose plus fructose was lost daily through respiration, which amounts to $18 \%$ to $39 \%$ of the carbon supply.

We computed the relative sweetness of each sugar for the 18 leaf : fruit treatment (Fig. 5). We presented the seasonal variation of relative sweetness because peach can be edible before ripening depending on the country and on the transformation processes. The contribution of sorbitol was never significant. The greatest contribution to total sweetness in June ( 80 to 100 DAB), when sucrose contributed only $30 \%$ to the flesh sweetness, came from fructose and to a lesser extent glucose. The importance of fructose was essentially due to its high sweetness rating. Sucrose was the main sweetener in July and August, when fruit flesh contained large amounts of it.

We analyzed the effects of changes in dry-weight growth curve parameters on sugar composition (Fig. 6). We limited our investigations to sucrose and fructose because the pattern of variation of glucose followed that of fructose closely and little sorbitol was present in the peach flesh. A single input parameter was changed in a ratio from 1 to 4 in each of the subsequent simulations. The reference conditions corresponded to 1993 and $\mathrm{wc}, \mathrm{DW}_{0}$, DWmax, $\mathrm{a}_{3}$, and $\mathrm{a}_{4}$ were set to $0.87,2.5,18.75,1.5$, and 30 , respectively. Increasing DWmax increased assimilate supply at the beginning or end of the flesh growth period, whereas increasing the maximum absolute growth rate $\left(a_{3}\right)$ increased assimilate supply at the middle of the flesh growth period. In both cases, there was a high increase in sugar accumulation, which was stronger toward the lower
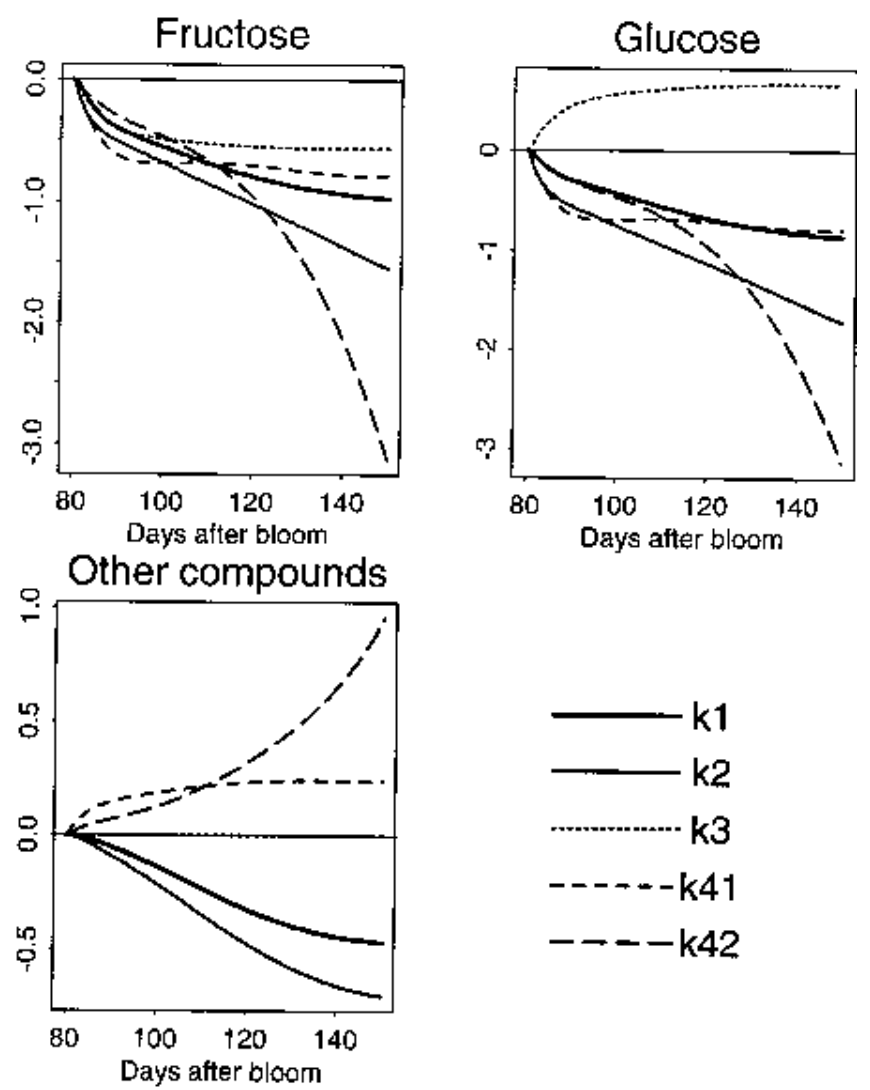

alues of the parameter range. The shape of simulated sugar accumulation curves were, in both cases, highly dependent on the temporal variations of assimilate supply. The sugar concentration at harvest (150 DAB) increased slightly with an increase in DWmax and $\mathrm{a}_{3}$, mainly because of the increase in sucrose. On the contrary, an increase in the date of the maximum absolute growth rate $\left(\mathrm{a}_{4}\right)$ had a slight positive effect on sugar accumulation and a strong positive effect on sucrose concentration. This effect was due to the timing of assimilate supply relative to that of carbon conversion from sucrose to reducing sugars and from reducing sugars to other compounds.

\section{Discussion}

A carbon flow approach was used in this paper as a framework for a deterministic model of sugar accumulation and metabolism during fruit growth. This approach contrasted with that of Keener et al. (1979) who based their approach on a mathematical description of a series of enzymatically regulated steps. The approach of Keener et al. (1979) requires an understanding of mechanisms for phloem unloading, metabolic pathways involved in sugar accumulation and metabolism, and compartmentation of sugars in the cell. As this information is only partly available in peach fruit, our model relied on less mechanistic hypotheses. It also contrasted with empirical models, such as that of Gonzalez et al. (1995) for kiwifruit, in which glucose, fructose, and sucrose contents were modeled as a function of the number of days since fruit set by polynomial regressions. The general agreement between simulated and field data for carbon partitioning into the various forms of sugar shows that our approach may be adequate for agronomical purposes. However, discrepancies between simulated and observed concentrations of glucose and fructose were significant. 
Improving the modeling of fruit water content, namely by considering its changes during fruit growth, may improve overall predictions. The basis for such improvement already exists in water flow models (Génard and Huguet, 1996; Lee, 1990). Moreover, our model does not consider that peach is a climacteric fruit. Such fruit are characterized by a surge of ethylene production at the onset of ripening, and it is recognized that ethylene plays an essential role in the ripening process, which greatly influences the sugar metabolism (Yang and Hoffman, 1984) and fruit respiration (Brady, 1987). Indole acetic acid (IAA) can promote ethylene production in many tissues (Yang and Hoffman, 1984), and changes in the measured levels of IAA and ethylene during stage III of growth follow similar trends in peaches (Miller et al., 1987). IAA being largely implicated in growth regulation, ethylene production certainly increases with fruit weight. An improvement of our model would be to consider the effect of growth on ethylene production, and, subsequently, the effect of ethylene on flesh respiration and on the model parameters implicated in sugar accumulation and synthesis

Several authors related a possible interconversion between glucose and fructose in different fruit (Hansen, 1970; Reid and Bieleski, 1974; Walker et al., 1978). This interconversion may exist in peach fruit, but our simplification of the model showed that it is not essential to the model. This choice was according to the hypotheses in the model of Keener et al. (1979). The sensitivity analysis showed that the quantity of reducing sugars depended similarly on parameters implicated in sorbitol supply $\left(\mathrm{k}_{1}\right)$, sucrose hydrolysis $\left(\mathrm{k}_{2}\right)$, and synthesis of compounds other than sugars $\left(\mathrm{k}_{41}\right.$,

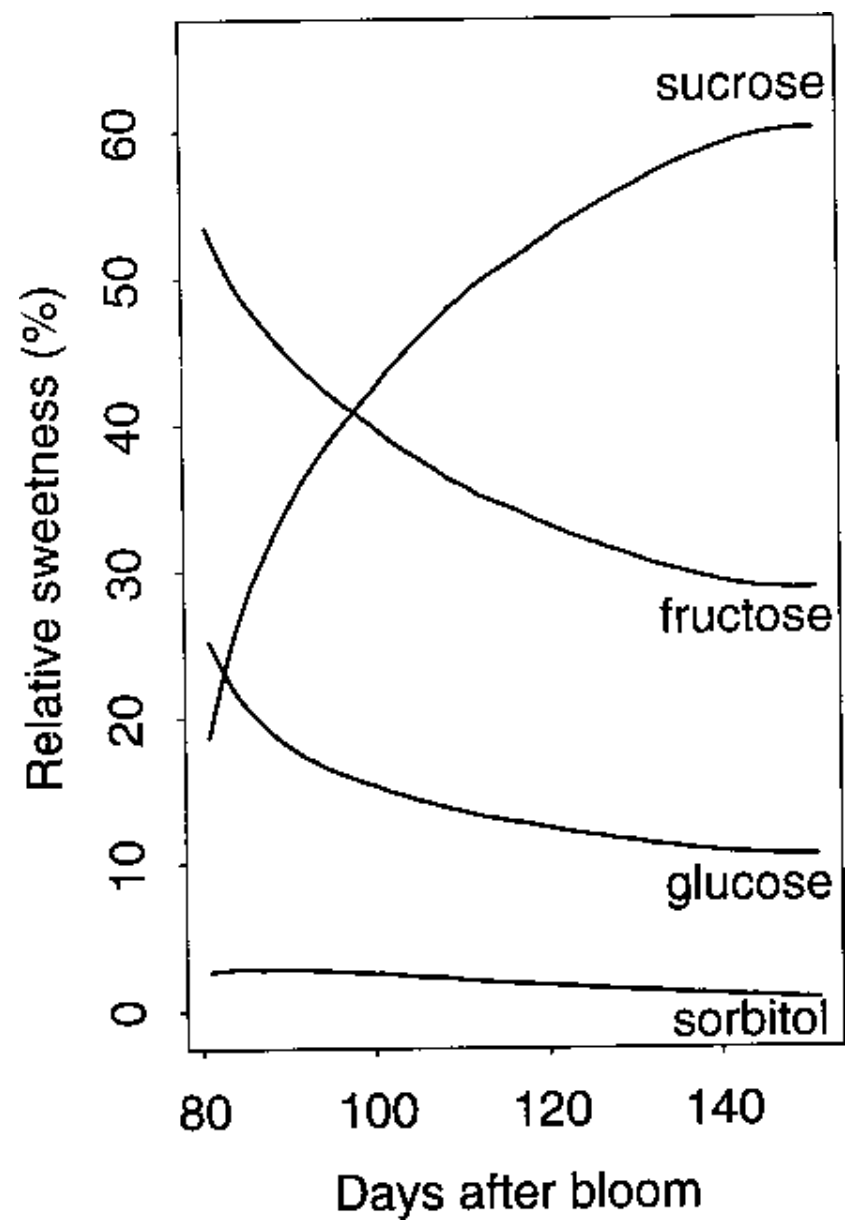

Fig. 5. Relative sweetness of sugars for fruit of treatment $t_{18}$ (18 leaves per fruit). $\mathrm{k}_{42}$ ). Only parameter $\mathrm{k}_{3}$, implicated in sorbitol conversion into reducing sugars, acted on glucose and fructose in the opposite way. This parameter was estimated to be $0.44 \mathrm{~d}^{-1}$, implying that most of the sorbitol was converted into fructose. This result is in contradiction with those of Moriguchi et al. (1990) on peach fruit, which suggest that sorbitol oxidase converts most of the sorbitol into glucose. However, the conversion of sorbitol to fructose was relevant in peach leaves (Moing et al., 1992) and several stone fruit (De Villiers et al., 1974; Reid and Bieleski, 1974). These differences may have resulted from a cultivar or a rootstock effect.

Parameter $\mathrm{k}_{1}$, which determines the proportion of sucrose and sorbitol in the phloem sap, had a significant effect on all carbohydrate forms in the sensitivity analysis. The value of this parameter was derived from a single paper (Moing et al., 1992), and we know nothing about its variations according to growth stage and conditions. Sensitivity analysis showed that the increase of parameters implicated in sucrose supply and hydrolysis $\left(\mathrm{k}_{1}\right.$ and $\left.\mathrm{k}_{2}\right)$ had a positive effect on sucrose and a negative effect on reducing sugars and others compounds. This showed that for a fixed assimilate supply, sucrose seems to conflict with reducing sugars and other compounds. Similarly, the variation of parameters implicated in the synthesis of compounds other than sugars $\left(\mathrm{k}_{41}\right.$ and $\left.\mathrm{k}_{42}\right)$ had opposite effects on these other compounds and on reducing sugars.

The proportion of sucrose converted every day into glucose and fructose decreased during the growing period to almost zero at harvest. Thus, the balance between sucrose and reducing sugars was less and less favorable to reducing sugars as the growing season progressed. This is in accord with the results of Vizzotto et al. (1996), which showed that sucrose hydrolyzing enzymes decline sharply with accumulation of sucrose, without a rise of enzymes implicated in synthetic activities. The percentage of glucose and fructose converted into compounds other than sugars decreased during the season to zero at harvest. This may have resulted from the decrease in cell wall growth during stage III of fruit growth and ripening (Bouranis and Niavis, 1992; Fishman et al., 1993).

Our simulations of the effect of changes in parameters of the growth curves explained in a comprehensive manner the relationship noted previously between flesh sugar contents at harvest and fruit growth (Génard et al., 1991). According to the results presented in that paper, there is a positive relationship between fruit growth and sucrose concentration in flesh at harvest and no clear relationship for reducing sugars. However, in the study of Génard et al. (1991), the main growth curve parameters (i.e., maximal cumulated growth, maximal absolute growth rate, and date of maximal absolute growth rate) were highly intercorrelated and the fruit with a high maximal cumulated growth also had a high maximal absolute growth rate, and their maximal absolute growth rate occurred late in the season. Our simulations suggest that increasing the maximal cumulated growth and the maximal absolute growth rate increased the total sucrose content of the fruit but had only a weak influence on the sucrose concentration of the flesh at harvest. The most influential parameter on sucrose concentration was the date of maximal absolute growth rate.

Our results showed that sugars present in low amounts, such as fructose, can have an important effect on flesh sweetness. Although sweetness is hard to measure and prediction equations often differ from one author to another, including sweetness in models is a first step toward predicting fruit quality.

In conclusion, the model we used predicts the sugar content of peaches with a fairly good accuracy over a range of fruit growth rates. However, its validation awaits further replication of study over several years, cultivars, and growing conditions. It requires 
parameters values, mean temperature, flesh water content, and flesh dry-weight growth curve data. Temperature data can be obtained from standard weather stations, and fruit-growth data can be generated from models such as that presented by Grossman and DeJong (1994) for peaches. Some parameters can be generic for the peach species, but most probably vary according to cultivars. In the future, connecting such a model with a fruit growth model would provide a basis for testing various orchard management strategies for improving fruit quality. Finally, this model may be used as a conceptual basis for modeling in other fruit species that do not accumulate starch, such as plums or apricots.

\section{Literature Cited}

Ackerman, J., M. Fisher, and R. Amado. 1992. Changes in sugars, acids, and amino acids during ripening and storage of apples (cv Glockenapfel). J. Agr. Food Chem. 40:1131-1134.

Bouranis, D.L. and C.A. Niavis. 1992. Cell wall metabolism in growing and ripening stone fruit. Plant Cell Physiol. 33:999-1008.

Brady, C.J. 1987. Fruit ripening. Annu. Rev. Plant Physiol. 38:155178.

Brooks, S.J., J.N. Moore, and J.B. Murphy. 1993. Quantitative and qualitative changes in sugar content of peach genotypes (Prunus persica L., Batsch.). J. Amer. Soc. Hort. Sci. 118:97-100.

Bruhn, C.M., N. Feldman, C. Garlitz, J. Harwood, E. Ivans, M. Marshall, A. Riley, D. Thurber, and E. Williamson. 1991. Consumer perceptions of quality: Apricots, cantaloupes, peaches, pears, strawberries, and tomatoes. J. Food Qual. 14:187-195.

Byrne, D.H., A.N. Nikolic, and E.E. Burns. 1991. Variability in sugars, acids, firmness and color characteristics of 12 peach genotypes. J. Amer. Soc. Hort. Sci. 116:10041006.

Chambers, J.M. and T.J. Hastie. 1992. Statistical models. S. Wadsworth \& Brooks/Cole Advanced Books \& Software, Pacific Grove, Calif.

Chapman, G.W., Jr., R.J. Horvat, and W.R. Forbus, Jr. 1991. Physical and chemical changes during the maturation of peaches (cv Majestic). J. Agr. Food Chem. 39:867-870.

Corelli-Grappadelli, L. and D.C. Coston. 1991. Thinning pattern and light environment in peach tree canopies influence fruit quality. HortScience 26:1464-1466.

Dann, I.R. and P.H. Jerie. 1988. Gradients in maturity and sugar levels of
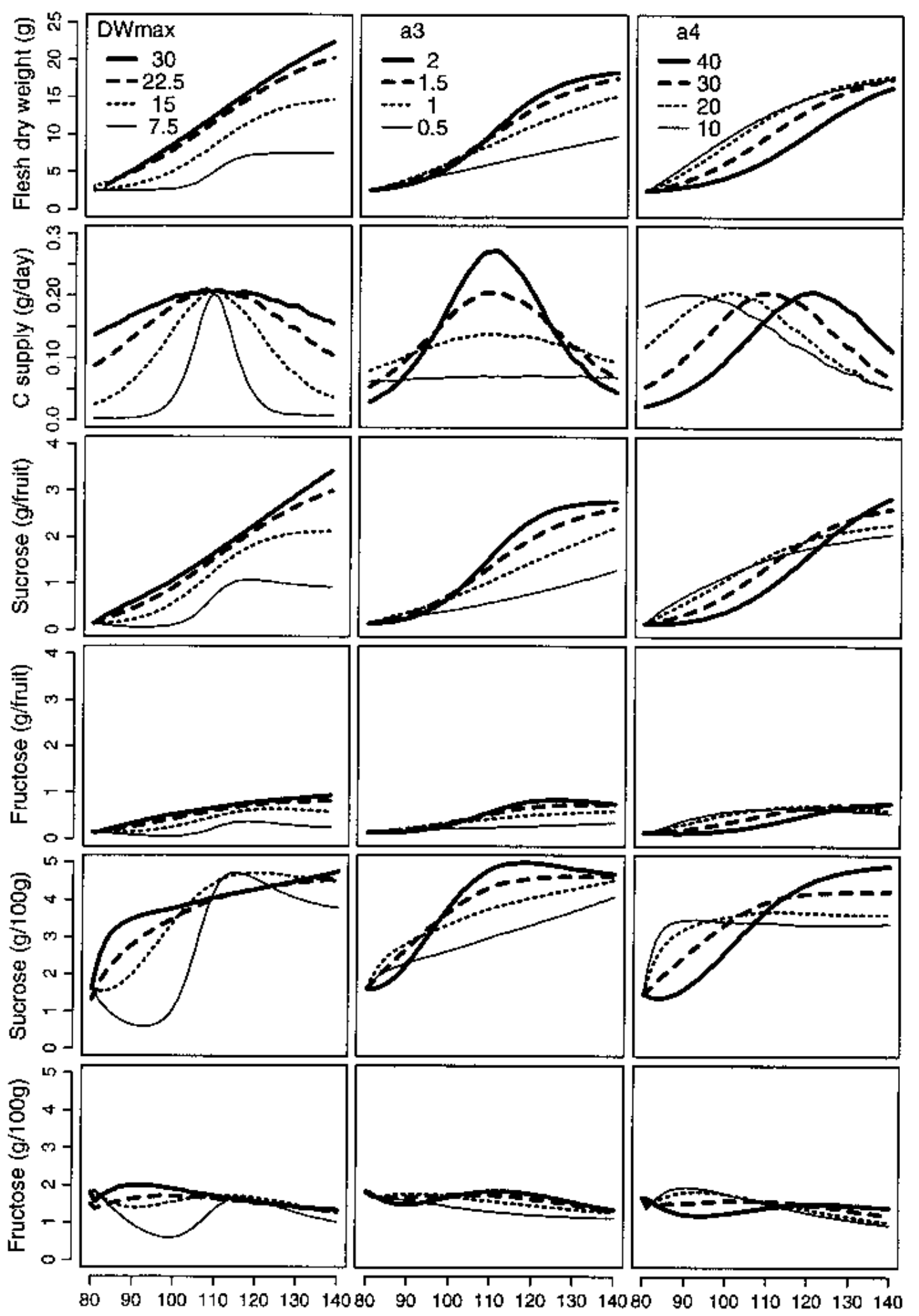
Fig. 6. Effects of changes in growth curve parameters DWmax $\left(a_{1}+a_{2}\right), a_{3}$, and $a_{4}$ on carbon supply, quantity per fruit of carbon
as sucrose and fructose, and sugar concentrations in flesh. fruit within peach trees. J. Amer. Soc. Hort. Sci. 113:27-31.

De Villiers, O.T., J.T. Meynhardt, and J.A. De Bruyn. 1974. The metabolism of sorbitol and sugars in Santa Rosa plums. Agroplantae 6:51-54. DeJong T.M. and J. Goudrian. 1989. Modeling peach fruit growth and carbohydrate requirements: reevaluation of the double sigmoid growth pattern. J. Amer. Soc. Hort. Sci. 114:800-804.

Doty, T.E. 1976. Fructose sweetness: A new dimension. Cereal Foods World 21:62-63.

Fishman, M.L., B. Levaj, D. Gillespie, and R. Scorza. 1993. Changes in 
the physicochemical properties of peach fruit pectin during on-tree ripening and storage. J. Amer. Soc. Hort. Sci. 118:343-349.

Gage, J. and G. Stutte. 1991. Developmental indices of peach: An anatomical framework. HortScience 26:459-463.

Génard, M. 1992. Influence du nombre de feuilles et de la répartition des fruits sur la production et la qualité des pêches. Can. J. Plant Sci. 72:517525.

Génard, M. and C. Bruchou. 1992. Multivariate analysis of within-tree factors accounting for the variation of peach fruit quality. Scientia Hort. 52:37-51.

Génard, M., C. Bruchou, and M. Souty. 1991. Variabilité de la croissance et de la qualité chez la pêche (Prunus persica $\mathrm{L}$. Batsch) et liaison entre croissance et qualité. Agronomie 11:829-845.

Génard, M. and J.G. Huguet. 1996. Modelling the response of peach fruit growth to water stress. Tree Physiol. 16:407-415.

Gonzalez, M.V., M.A. Lage, and P. Paseiro. 1995. Time dependence of physico-chemical characteristics of kiwifruit between fruitset and harvest in Galicia (NW Spain). J. Hort. Sci. 1995, 70:297-301.

Grossman, Y.L., and T.M. Dejong. 1994. Peach: A simulation model of reproductive and vegetative growth in peach trees. Tree Physiol. 14:329_ 345.

Hansen, P. 1970. ${ }^{14} \mathrm{C}$-studies on apple trees. V. Translocation of labelled compounds from leaves to fruit and their conversion within the fruit. Physiol. Plantarum 23:564-573.

Hubbard, N.L., D.M. Pharr, and S.C. Huber. 1991. Sucrose phosphate synthase and other sucrose metabolizing enzymes in fruit of various species. Physiol. Plantarum 82:191-196.

Ishida, M., A. Inaba, and Y. Sobajima. 1971. Seasonal changes in the concentration of sugars and organic acids in peach fruit. Scientific Rpt. Kyoto Prefectural Univ. Agr. 23:18-23.

Keener, M.E., D.W. De Michele, and P.J.H Sharpe. 1979. Sink metabolism. A conceptual framework for analysis. Ann. Bot. 44:659-669.

Kliewer, W.M. and R.J. Weaver. 1971. Effect of crop level and leaf area on growth, composition and coloration of Tokay grapes. Amer. J. Enol. Viticult. 22:172-177.

Kulp, K., K. Lorenz, and M. Stone. 1991. Functionality of carbohydrates ingredients in bakery products. Food Technol. March:136-142.

Lee, D.R. 1990. A unidirectional water flux model of fruit growth. Can. J. Bot. 68:1286-1290.

Leonard, S., B.S Luh, and E. Hinreiner. 1953. Flavor evaluation of canned cling peaches. Food Technol. 480-485.

Marini, R.P. and J.R. Trout. 1984. Sampling procedures for minimizing variation in peach fruit quality. J. Amer. Soc. Hort. Sci. 109:361-364.

Marini, R.P., D. Sowers, and M.C. Marini. 1991. Peach fruit quality is affected by shade during final swell of fruit growth. J. Amer. Soc. Hort. Sci. 116:383-389.

Miller, A.N., C.S. Walsh, and J.D. Cohen. 1987. Measurement of Indole3-Acetic Acid in peach fruit (Prunus persica L. Batsch cv Redhaven) during development. Plant Physiol. 84:491-494.
Moing, A., F. Carbonne, M.H. Rashad, and J.P. Gaudillère. 1992. Carbon fluxes in mature peach leaves. Plant Physiol. 100:1578-1884.

Moriguchi, T., K. Abe, T. Sanada, and S. Yamaki. 1992. Levels and role of sucrose synthase, sucrose-phosphate synthase, and acid invertase in sucrose accumulation in fruit of Asian pear. J. Amer. Soc. Hort. Sci. 117:274-278.

Moriguchi, T., T. Sanada, and S. Yamaki. 1990. Seasonal fluctuations of some enzymes relating to sucrose and sorbitol metabolism in peach fruit. J. Amer. Soc. Hort. Sci. 115:278-281.

Pangborn, R.M. 1963. Relative taste intensities of selected sugars and organic acids. J. Food Sci. 28:726-733.

Pavel, E.W. and T.M. DeJong. 1993. Relative growth rate and its relationship to compositional changes of nonstructural carbohydrates in the mesocarp of developing peach fruit. J. Amer. Soc. Hort. Sci. 118:503508.

Pavel, E.W. and T.M. DeJong. 1995. Seasonal patterns of nonstructural carbohydrates of apple (Malus pumila Mill.) fruit. Relationship with relative growth rates and contribution to solute potential. J. Hort. Sci. 70:127-134.

Reid, M.S. and R.L. Bieleski. 1974. Sugar changes during fruit ripening. Whither sorbitol?, p. 823-830. In: R.L. Bieleski, A.R. Ferguson, M.M. Cresswell (eds.). Mechanisms of regulation of plant growth. Bul. 12, Royal Soc. N.Z., Wellington.

Robertson, J.A., F.I. Meredith, and R. Scorza. 1988. Characteristics of fruit from high and low-quality peach cultivars. HortScience 23:1032-1034.

Robertson, J.A., F.I. Meredith, B.G Lyon, G.W. Chapman, and W.B. Sherman. 1992. Ripening and cold storage changes in the quality characteristics of non-melting clingstone peaches (Fla 9-20C). J. Food Sci. 57:462-465.

Souty, M. and P. André. 1975. Composition biochimique et qualité des pêches. Ann. Technol. Agr. 24:217-236.

Steiner, E.C., G.E. Blau, and G.L. Agin. 1993. SimuSolv. Modeling and simulation software. Dow Chemical Co., Midland, Mich.

Vizzotto, G., Pinton R., Varani Z., and G. Costa. 1996. Sucrose accumulation in developing peach fruit. Physiologia Plantarum 96:225-230.

Walker, A.J., L.C. Ho, and D.A. Baker. 1978. Carbon translocation in the tomato: Pathways of carbon metabolism in the fruit. Ann. Bot. 42:901909.

Yamaguchi, S., T. Yoshikawa, S. Ikeda, and T. Ninomiya. 1970. Studies on the taste of some sweet substances. Part I. Measurement of the relative sweetness. Agr. Biol. Chem. 34:181-186.

Yamaki, S. and K. Ishikawa. 1986. Roles of four sorbitol related enzymes and invertase in the seasonal alteration of sugar metabolism in apple tissue. J. Amer. Soc. Hort. Sci. 111:134-137.

Yamaki, S. and T. Asakura. 1988. Energy coupled transport of sorbitol and other sugars into the protoplast isolated from apple fruit flesh. Plant Cell Physiol. 29:961-967.

Yang, S.F. and N.E. Hoffman. 1984. Ethylene biosynthesis and its regulation in higher plants. Ann. Rev. Plant Physiol. 35:155-189. 